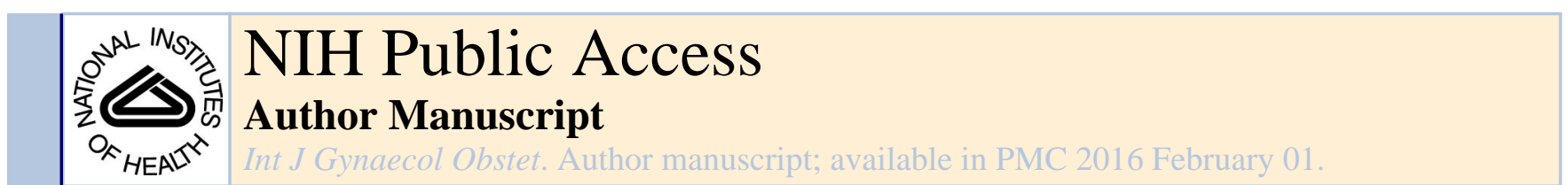

Published in final edited form as:

Int J Gynaecol Obstet. 2015 February ; 128(2): 169-173. doi:10.1016/j.ijgo.2014.08.014.

\title{
Examining negative effects of early life experiences on reproductive and sexual health among female sex workers in Tijuana, Mexico
}

\author{
Karishma K. Oza ${ }^{a}$, Jay G. Silverman ${ }^{b}$, letza Bojorquez ${ }^{c}$, Steffanie A. Strathdee ${ }^{b}$, and Shira \\ M. Goldenberg ${ }^{\mathrm{d}}{ }^{*}$ \\ a Gillings School of Global Public Health, Department of Maternal and Child Health, University of \\ North Carolina at Chapel Hill, Chapel Hill, NC, USA \\ b Division of Global Public Health, University of California, San Diego School of Medicine, San \\ Diego, CA, USA \\ c Department of Population Studies, El Colegio de la Frontera Norte, Tijuana, Mexico \\ d Gender and Sexual Health Initiative, British Columbia Centre for Excellence in HIV/AIDS, \\ Division of AIDS, Department of Medicine, University of British Columbia, Vancouver, BC, \\ Canada
}

Abstract

Objective-To explore experiences during childhood and adolescence that influenced reproductive and sexual health among women who had entered the sex industry in adolescence.

Methods-A qualitative study was conducted using information provided by 25 female sex workers (FSWs) from Tijuana, Mexico, who reported entering the sex industry when younger than 18 years. In-depth, semi-structured interviews were conducted with all participants between January 31, 2011, and July 8, 2011.

Results-Four interrelated themes that shaped health experiences-early sexual abuse, early illicit drug use, ongoing violence, and limited access to reproductive and sexual health care-were identified. Participants reporting these experiences were at risk of unintended teenaged pregnancy, spontaneous abortion or stillbirth, and untreated sexually transmitted infections.

Conclusion-Programs and policies that address social, structural, and individual vulnerabilities during adolescence and adulthood are required to promote reproductive and sexual health among FSWs in Tijuana, Mexico.

\footnotetext{
(C) 2014 International Federation of Gynecology and Obstetrics. Published by Elsevier Ireland Ltd. All rights reserved.

* Corresponding author: Shira M. Goldenberg Gender and Sexual Health Initiative, British Columbia Centre for Excellence in HIV/ AIDS, Division of AIDS, Department of Medicine, University of British Columbia, 608-1081 Burrard Street, Vancouver, BC V6Z 1Y6, Canada. Tel.: +1 6046822344 ext.66268; fax: +1 604806 8464. sgoldenberg @ cfenet.ubc.ca.

Publisher's Disclaimer: This is a PDF file of an unedited manuscript that has been accepted for publication. As a service to our customers we are providing this early version of the manuscript. The manuscript will undergo copyediting, typesetting, and review of the resulting proof before it is published in its final citable form. Please note that during the production process errors may be discovered which could affect the content, and all legal disclaimers that apply to the journal pertain.

Conflict of interest

The authors have no conflicts of interest.
} 


\section{Keywords}

Drug use; Equity in access; Equity in health; Female sex work; Gender-based violence;

Reproductive health; Sexual health; Tijuana

\section{Introduction}

Worldwide, the prevalences of unintended pregnancy, induced abortion, spontaneous abortion, sexually transmitted infections (STIs), and HIV infection are higher in female sex workers (FSWs) than in the general population [1-7]. High rates of childhood sexual abuse $[8,9]$, adolescent involvement in the sex industry [10,11], and adolescent illicit drug use $[12,13]$ have been linked to inconsistent condom use and HIV infection among FSWs [10]. These health disparities are shaped by broad social and structural determinants such as stigma and marginalization, gender-based violence, and inequalities, as well as policies surrounding sex work and their enforcement $[10,14,15]$.

Experiences during childhood and adolescence that contribute to poor health across the life course are understudied among FSWs. Global evidence indicates that $20 \%-40 \%$ of FSWs enter the sex industry at an early age ( $\leq 8$ years) [7]. One study conducted in Ciudad Juarez and Tijuana, Mexico [10], found that $41 \%$ of FSWs had a history of sex exchange before the age of 18 years, a situation that seems to confer a disproportionately increased risk of adverse sexual health outcomes, including STIs and infection with HIV $[3,7,10]$.

The Mexican border city of Tijuana hosts thriving markets for child sex tourism and illicit drug use $[10,16,17]$. Sex work has a quasi-legal status and is concentrated in the city's red light district, where public health regulations require FSWs to pay for health permits and undergo monthly STI testing. Nevertheless, many FSWs work without permits [16], which are only available to adults aged at least 18 years [10]. Despite these regulations, adolescent sex exchange is highly visible on the streets of Tijuana.

High rates of STIs, HIV infection, reproductive health inequities, and gender-based violence have been reported among FSWs in Tijuana [14-19]. A study conducted among adult FSWs [18] found high prevalences of spontaneous abortion and/or stillbirth (30\%), sexual violence (51\%), and physical violence (49\%). These rates are higher than are those observed among the general population of women in Mexico, which have been reported as 5 per 1000 live births, $8.4 \%$, and $46.7 \%$, respectively [20,21].

Despite evidence suggesting elevated vulnerabilities associated with early involvement in the sex industry [8-12], little is known about how experiences during childhood and adolescence shape long-term reproductive and sexual health. In particular, qualitative evidence is lacking regarding early social and structural experiences, such as violence and access to care, and how these factors influence reproductive and sexual health across the life course. Therefore, the aim of the present study was to qualitatively explore this issue among FSWs with a history of adolescent sex exchange in Tijuana, Mexico. 


\section{Materials and methods}

A qualitative analysis was performed using data supplied by 25 women from Tijuana who had enrolled in a larger mixed-methods study (Proyecto Parejas). The Proyecto Parejas study was conducted in Tijuana and Ciudad Juarez among 214 FSWs who had been recruited through targeted sampling in areas where sex work and drug use were known to occur [19]. They were eligible if they were aged at least 18 years, had traded sex in the past month, reported having used illicit drugs at some point in their lifetime, and had a male intimate partner.

In-depth, semi-structured interviews were conducted with 31 FSWs between January 31, 2011 and July 8, 2011. Eligibility criteria for the qualitative interviews included being a Proyecto Parejas participant who reported entering the sex industry during adolescence (before 18 years of age) or being forced or coerced into the sex industry, as previously described [22]. Interview participants were purposively sampled to reflect a range of ages, nationalities, and health experiences [22]. The present analysis was restricted to a subset of interviews with 25 women who reported entering the sex industry during adolescence. Institutional review boards at the University of California, San Diego, and El Colegio de la Frontera Norte in Tijuana approved the present study. All participants provided written informed consent.

Interviews lasted approximately 1.5 hours, were conducted in Spanish or English depending on the interviewee's preference, and were audiotaped in private offices. Interviews were conducted by trained female interviewers, including staff hired from a local communitybased organization, a medical student, and the principal investigator (S.M.G.). Interviewers followed WHO guidelines for interviewing trafficked women [23] to ensure a professional, ethical, and safe environment for individuals in potentially dangerous or exploitative relationships. Questions were pilot-tested and revised as data collection and analysis progressed. Interviewers prioritized listening and were prepared to address participants' needs. Questions that provoked an emotional response were avoided. Participants were asked to reflect upon their entry into, and continuation of, sex work; reproductive and sexual health concerns; access to health care; sexual, physical, or psychological abuse and/or violence; substance use; migration history; and interactions with government authorities.

When necessary, interviews were transcribed and translated from Spanish to English. All names were replaced by pseudonyms to protect confidentiality. Participants received US $\$ 20$, condoms, prevention information, and referrals to support. Additional methodological details are described elsewhere [22]. Quantitative data from Proyecto Parejas were used to derive sociodemographic characteristics.

Data were coded by the same researcher (K.O.), working in close collaboration with the study team. The constant comparative method was used to generate an initial list of emerging concepts using NVivo version 9.0 (QSR International, Doncaster, VIC, Australia). Memos were used to document and categorize initial ideas and themes. A strong emphasis on childhood and adolescent experiences (e.g. violence, drug use, high-risk sexual encounters, and complications of pregnancy) emerged during the coding process. 
A spreadsheet was maintained to document similarities and differences in participants' life course and experiences. Codes were conceptually organized into overarching themes that were revised and regrouped until a consensus on a set of codes that most comprehensively represented key emerging themes was reached. Coding was supplemented using text search queries to ensure all relevant data were captured.

To ensure rigor, coding decisions were regularly discussed at team meetings; questions, decisions, and observations on coding were noted through memos and audit trails, and a codebook was maintained. Attention was paid to analyzing narratives that both supported and challenged key concepts. The research process and findings were presented to peers at the University of California, San Diego's Division of Global Public Health to gather input and establish credibility. To further assess the validity of the findings, feedback was elicited from a subgroup of six former participants who agreed to a follow-up interview. A reproductive health workshop for FSWs was also conducted in Tijuana.

\section{Results}

The median age at both sex industry entry and first pregnancy was 16 years (Table 1). Overall, 11 (46\%) of 24 participants who reported at least one previous pregnancy had experienced at least one spontaneous abortion.

Four key themes were identified that appeared to influence reproductive and sexual health experiences: early sexual abuse, early illicit drug use, ongoing violence, and limited sexual and reproductive health care (Table 2). Most participants shared a common trajectory of early sexual abuse by relatives, quitting school and leaving the family home, illicit drug use and sex work during adolescence, and poor access to reproductive and sexual health care.

Of the 25 FSWs interviewed, 10 (40\%) described past physical, sexual, or emotional abuse by a parent or caregiver. Of the eight participants who experienced rape, all had been raped for the first time when aged 18 years or younger (median 14 years). Perpetrators were most frequently male relatives or neighbors (Table 2).

Among the women who had been abused during childhood, most had left home at an early age, which often resulted in street involvement (e.g. homelessness or involvement in street drug economies) and use of illicit drugs during adolescence (Table 2). Housing instability following sexual abuse seemed to place these women in situations of elevated vulnerability to sexual violence and unprotected sex during adolescence. For example, after running away from home, Selena was raped while spending the night alone at the house of her sister's friend, which resulted in an unintended pregnancy (Table 2). In the years following this incident, Selena experienced two unintended pregnancies, an induced abortion, and a spontaneous abortion, illustrating the overlapping harms experienced by women interviewed in the present study. Similarly, after leaving home because of sexual abuse and drug use, Luisa met her first partner at a correctional facility, where she experienced an unintended pregnancy and spontaneous abortion when aged 14 years.

Most participants had used illicit drugs in the 6 months before the interview (Table 1). Most had initially used marijuana and inhalants (e.g. glue or paint thinner) during adolescence, but 
had then quickly progressed to "harder" illicit drugs such as heroin and crystal methamphetamine. Peers, intimate partners, relatives, and drug-oriented environments provided early exposure to these substances. Acceptance into adolescent peer networks was closely linked to experiences of sexual coercion in the context of illicit drug use. This situation is illustrated by the experiences of Sofia and Maria, who described instances in which pressure and coercion to use drugs by intimate partners and gang members resulted in unwanted sexual activity, including rape (Table 2).

Several participants who had been pregnant had been unaware of their pregnancy status during the first trimester; because most of these experiences occurred during adolescence, they were probably uninformed of the dangers of illicit drug use during pregnancy. One participant (Viviana) attributed the premature death of her infant, who was born with a developmental disorder (anencephaly), to the use of crystal methamphetamine. Both her story and that of Alejandra illustrate the perceived consequences of early illicit drug use on reproductive and sexual health.

Overall, 18 (72\%) participants reported violence, including sexual abuse, which began during childhood and persisted through adolescence and adulthood. These experiences included violence both within and outside the context of sex work that was perpetrated by partners, third parties (e.g. pimps), clients, gang members, and police officers. Participants described spontaneous abortions and other negative reproductive and sexual health consequences of violence by intimate partners, clients, and pimps. For example, one participant (Norma) experienced a spontaneous abortion after her partner pushed her during an argument. Selena, who had a history of childhood sexual abuse and two unintended pregnancies, entered the sex industry when aged 16 years (Table 2). Her first intimate partner, a pimp twice her age, frequently beat her to the extent that she was unrecognizable. Although she was eventually able to escape from the Tijuana hotel rooms he kept her locked in, Selena never reported him to the police. After these initial violent experiences, women such as Selena reported continued exposure to violence by different partners, highlighting the complex gender and power dynamics in this setting [24].

Despite these alarming health and social vulnerabilities, 16 (64\%) women interviewed reported little or no access to health care during adolescence. Participants reported difficulty in accessing reproductive and sexual health care throughout their life course, a situation often exacerbated by stigma and marginalization by providers owing to drug use and/or sex work (Table 2).

The participants reported limited knowledge of contraceptive options and their correct use. Some of the older women, such as Luisa and Juliana (aged 40 and 36 years, respectively), recalled not knowing what a condom was or how to put one on during adolescence. Twenty (80\%) women reported barriers to accessing and negotiating condom use, especially during adolescence. Luisa and Adriana linked these barriers to STIs, unintended pregnancy, and infant mortality (Table 2). For example, before receiving an STI diagnosis, Luisa had never used a condom, and attributed this lack of awareness to her small-town upbringing. 
Limited affordability, availability, and adequacy of nonjudgmental medical services were identified as structural barriers to accessing care. Physical barriers included distance to clinics, stigmatization by health care providers (Table 2), and an inability to obtain the health permits required to access routine municipal testing for HIV and/or STIs.

Fear of providers and unsafe self-care practices often resulted from limited access to health services. Some participants expressed a desire for access to abortion services in the case of unintended pregnancies. For example, Liliana self-administered an injection to her stomach upon learning that she was pregnant, in the hope that it would cause a spontaneous abortion. At the time of the interview, Liliana reported four pregnancies, two of which led to live births.

\section{Discussion}

The present study found that early sexual abuse, early use of illicit drugs, ongoing violence, and limited access to medical services have large effects on reproductive and sexual health among FSWs from Tijuana with a history of adolescent sex exchange. Drug use and barriers to condom use during adolescence both contributed to reproductive and sexual health vulnerabilities. However, the findings of the present study also clearly document how early social and structural exposures - such as poverty, gender-based inequities, violence, unsafe living conditions, stigma, and marginalization—could perpetuate reproductive and sexual health disparities.

Narratives of the women enrolled in the present study suggested that childhood sexual abuse and leaving home were antecedents to early initiation in the sex industry. Rape was first experienced between the ages of 5 and 18 years among the eight participants who reported this form of sexual abuse, a finding that indicated early vulnerability to sexual violence [18]. Although early illicit drug use can represent a coping mechanism for sexual abuse [11], progression from "entry-level" drugs (e.g. marijuana and inhalants) to "hard" drugs (e.g. heroin and crystal methamphetamine) seemed to place participants at elevated risk for unwanted sexual activity and reproductive and sexual health harms.

Ongoing exposure to violence was exacerbated by engrained societal norms and structural violence. Participants reported limited ability to negotiate condom use with clients during adolescence, echoing a study of FSWs in Thailand [25]. This finding is also in line with a previously published study [10] that uncovered an increased demand for unprotected sex with adolescent girls owing to clients' perceptions of a lowered risk of acquiring an STI and/or HIV. In the present study, recurring experiences of forced or coerced unprotected sex with no other form of contraception placed women at risk for unintended pregnancy, STIs, and infection with HIV, similar to findings among FSWs in Russia [4].

The findings of the present study add to global evidence suggesting that FSWs experience pervasive barriers to sexual and reproductive health services, but are uniquely focused on these barriers within the context of adolescent sex exchange. Approximately one-third of participants had never received a gynecologic check-up, a finding in agreement with another study [25]. Stigma and fear of providers were noted to be key barriers to accessing 
appropriate medical services. These findings underscore the need to increase access to nonjudgmental, accessible health care for adolescents as well as adults in the sex industry.

In the present study, the median number of pregnancies per woman (three) was consistent with findings among FSWs in Tijuana and Ciudad Juarez with a history of injecting drug use [18]. Notably, the median ages at both first pregnancy and at sex industry entry were the same in the present study (16 years), with narratives linking economic needs surrounding unintended pregnancy to adolescent sex industry entry [11].

The present study was a secondary analysis of data collected to examine the relationship between sex industry entry, migration, and infection with HIV [22]; therefore, interview responses might not represent the experiences of all FSWs in Mexico or elsewhere. Participants were asked to retrospectively describe events that had occurred during adolescence, and FSWs who are younger than 18 years might have different perspectives than do those who were interviewed in the present study. Nevertheless, the findings are relevant to efforts to promote reproductive and sexual health among marginalized women in settings where adolescent sex exchange and illicit drug use occur.

High-quality, evidence-based, multi-level interventions_-such as combined behavioral, clinical, and structural interventions - are needed to reduce sexual health inequities, infant and maternal mortality, and unsafe practices surrounding abortion and self care [20,24]. Tailored programs that engage adolescents who exchange sex in appropriate reproductive and sexual health care remain crucial [7], especially given the evidence that unintended consequences of laws prohibiting health permits for adolescents can include barriers to STI treatment and prevention [14-17].

Trauma-informed interventions to support marginalized young women, such as programs relying on peers (e.g. formerly homeless young people or sex workers) or the community (e.g. non-governmental organizations or counselors) can provide support and information about contraception, sexual and reproductive health services, and violence [24]. Effective programs that empower young women to remain in school could also be beneficial, given the low level of formal education reported by participants in the present study. The women involved in the present study also shared possible solutions to improving health and wellbeing among young women and FSWs in Tijuana, which included providing alternative economic opportunities (e.g. job training and placements), effective drug treatment programs, shelters, and psychological support for survivors of violence [24].

In conclusion, the findings of the present study suggest that detrimental early life experiences negatively influence reproductive and sexual health among FSWs. Future research should focus on health and human rights issues surrounding adolescents working in the sex industry, including exploration of effective mechanisms to overcome barriers to care, especially for street-involved, homeless young women. In addition, prenatal care and the birthing environments of marginalized young women, and potential cyclical or generational aspects of sex work, require further examination. 


\section{Acknowledgments}

Financial support for the present study was provided by the Berkeley Health Initiative of the Americas' Programa de Investigación en Migración y Salud (Research Program on Migration and Health) and the National Institutes of Health (National Institute on Drug Abuse R01 DA027772). Views expressed are not necessarily reflective of those of the National Institute on Drug Abuse or the National Institutes of Health.

\section{References}

1. Miller CL, Fielden SJ, Tyndall MW, Zhang R, Gibson K, Shannon K. Individual and structural vulnerability among female youth who exchange sex for survival. J Adolesc Health. 2011; 49(1): 36-41. [PubMed: 21700154]

2. Baral S, Beyrer C, Muessig K, Poteat T, Wirtz AL, Decker MR, et al. Burden of HIV among female sex workers in low-income and middle-income countries: a systematic review and meta-analysis. Lancet Infect Dis. 2012; 12(7):538-49. [PubMed: 22424777]

3. Couture MC, Sansothy N, Sapphon V, Phal S, Sichan K, Stein E, et al. Young women engaged in sex work in Phnom Penh, Cambodia, have high incidence of HIV and sexually transmitted infections, and amphetamine-type stimulant use: new challenges to HIV prevention and risk. Sex Transm Dis. 2011; 38(1):33-9. [PubMed: 21085056]

4. Decker MR, Yam EA, Wirtz AL, Baral SD, Peryshkina A, Mogilnyi V, et al. Induced abortion, contraceptive use, and dual protection among female sex workers in Moscow, Russia. Int J Gynecol Obstet. 2013; 120(1):27-31.

5. Rodrigues T, Rocha L, Barros H. Physical abuse during pregnancy and preterm delivery. Am J Obstet Gynecol. 2008; 198(2):171, e1-6. [PubMed: 17905171]

6. Shannon K, Bright V, Gibson K, Tyndall MW, Maka Project Partnership. Sexual and drug-related vulnerabilities for HIV infection among women engaged in survival sex work in Vancouver, Canada. Can J Public Health. 2007; 98(6):465-9. [PubMed: 19039884]

7. Silverman JG. Adolescent female sex workers: invisibility, violence and HIV. Arch Dis Child. 2011; 96(5):478-81. [PubMed: 21357241]

8. Widom CS, Kuhns JB. Childhood victimization and subsequent risk for promiscuity, prostitution, and teenage pregnancy: a prospective study. Am J Public Health. 1996; 86(11):1607-12. [PubMed: 8916528]

9. Dickson-Gómez J, Bodnar G, Gueverra A, Rodriguez K, Mauricio G. Childhood sexual abuse and HIV risk among crack-using commercial sex workers in San Salvador, El Salvador: a qualitative analysis. Med Anthropol Q. 2006; 20(4):545-74. [PubMed: 17225658]

10. Goldenberg SM, Rangel G, Vera A, Patterson TL, Abramovitz D, Silverman JG, et al. Exploring the impact of underage sex work among female sex workers in two Mexico-US border cities. AIDS Behav. 2012; 16(4):969-81. [PubMed: 22012147]

11. Loza O1, Strathdee SA, Lozada R, Staines H, Ojeda VD, Martínez GA, et al. Correlates of early versus later initiation into sex work in two Mexico-U.S. border cities. J Adolesc Health. 2010; 46(1):37-44. [PubMed: 20123256]

12. Weber AE, Boivin JF, Blais L, Haley N, Roy E. HIV risk profile and prostitution among female street youths. J Urban Health. 2002; 79(4):525-35. [PubMed: 12468672]

13. El-Bassel N, Witte SS, Wada T, Gilbert L, Wallace J. Correlates of partner violence among female street-based sex workers: substance abuse, history of childhood abuse, and HIV risks. AIDS Patient Care STDS. 2001; 15(1):41-51. [PubMed: 11177587]

14. Beletsky L, Martinez G, Gaines T, Nguyen L, Lozada R, Rangel G, et al. Mexico's northern border conflict: collateral damage to health and human rights of vulnerable groups. Rev Panam Salud Publica. 2012; 31(5):403-10. [PubMed: 22767041]

15. Sirotin N, Strathdee SA, Lozada R, Nguyen L, Gallardo M, Vera A, et al. A comparison of registered and unregistered female sex workers in Tijuana, Mexico. Public Health Rep. 2010; 125(Suppl 4):101-9. [PubMed: 20626197] 
16. Patterson TL, Semple SJ, Fraga M, Bucardo J, de la Torre A, Salazar J, et al. Comparison of sexual and drug use behaviors between female sex workers in Tijuana and Ciudad Juarez, Mexico. Subst Use Misuse. 2006; 41(10-12):1535-49. [PubMed: 17002992]

17. Strathdee SA, Philbin MM, Semple SJ, Pu M, Orozovich P, Martinez G, et al. Correlates of injection drug use among female sex workers in two Mexico-U.S. border cities. Drug Alcohol Depend. 2008; 92(1-3):132-40. [PubMed: 17714888]

18. McDougal L, Strathdee SA, Rangel G, Martinez G, Vera A, Sirotin N, et al. Adverse pregnancy outcomes and sexual violence among female sex workers who inject drugs on the United StatesMexico border. Violence Vict. 2013; 28(3):496-512. [PubMed: 23862312]

19. Syvertsen JL, Robertson AM, Abramovitz D, Rangel MG, Martinez G, Patterson TL, et al. Study protocol for the recruitment of female sex workers and their noncommercial partners into couplebased HIV research. BMC Public Health. 2012; 12:136. [PubMed: 22348625]

20. Lawn, JE.; Kinney, M. [June 25, 2014] Stillbirths: An executive summary for The Lancet's Series. http://download.thelancet.com/flatcontentassets/series/stillbirths.pdf. Published April 14, 2011.

21. [June 25, 2014] UN Women. Violence against Women Prevalence Data: Surveys by Country. http://www.endvawnow.org/uploads/browser/files/vawprevalence_matrix_june2013.pdf. Published 2013.

22. Goldenberg S, Silverman J, Engstrom D, Bojorquez-Chapela I, Strathdee S. "Right here is the gateway": Mobility, sex work entry and HIV risk along the Mexico-US border. Int Migr. 2014; 52(4):26-40. [PubMed: 25346548]

23. Zimmerman, C.; Watts, C. [July 15, 2012] WHO ethical and safety recommendations for interviewing trafficked women. http://www.who.int/mip/2003/other_documents/en/ Ethical_Safety-GWH.pdf. Published 2003.

24. Goldenberg SM, Engstrom D, Rolon ML, Silverman JG, Strathdee SA. Sex workers perspectives on strategies to reduce sexual exploitation and HIV risk: a qualitative study in Tijuana, Mexico. PLoS One. 2013; 8(8):e72982. [PubMed: 24023661]

25. Decker MR, McCauley HL, Phuengsamran D, Janyam S, Silverman JG. Sex trafficking, sexual risk, sexually transmitted infection and reproductive health among female sex workers in Thailand. J Epidemiol Community Health. 2011; 65(4):334-9. [PubMed: 20515895] 


\section{Synopsis}

Early sexual abuse, early illicit drug use, ongoing violence, and limited access to medical services negatively affected reproductive and sexual health among female sex workers. 


\section{Table 1}

Sociodemographic characteristics, reproductive and sexual health indicators, and sexual violence among female sex workers in Tijuana, Mexico $(\mathrm{n}=25){ }^{a},{ }^{b}$

\begin{tabular}{ll}
\hline Variable & Value \\
\hline Age, y & $33(19-45)$ \\
Age at sex industry entry, y & $16(12-17)$ \\
Education, y & $6(1-12)$ \\
Pregnancies & $3(0-9)$ \\
Age at first pregnancy, y $c$ & $16(14-28)$ \\
One or more spontaneous abortion $c$ & $11(46)$ \\
Illicit drug use in the 6 months before interview & $23(92)$ \\
Tested positive for any STI and/or HIV & $5(20)$ \\
Ever received a gynecologic check-up & $16(64)$ \\
Ever raped & $8(32)$ \\
Age when first raped, y & $14(5-18)$ \\
\hline Abbreviation: STI, sexually transmitted infection. & \\
${ }^{a}$ Valculated among the 24 participants who reported at least one previous pregnancy.
\end{tabular}




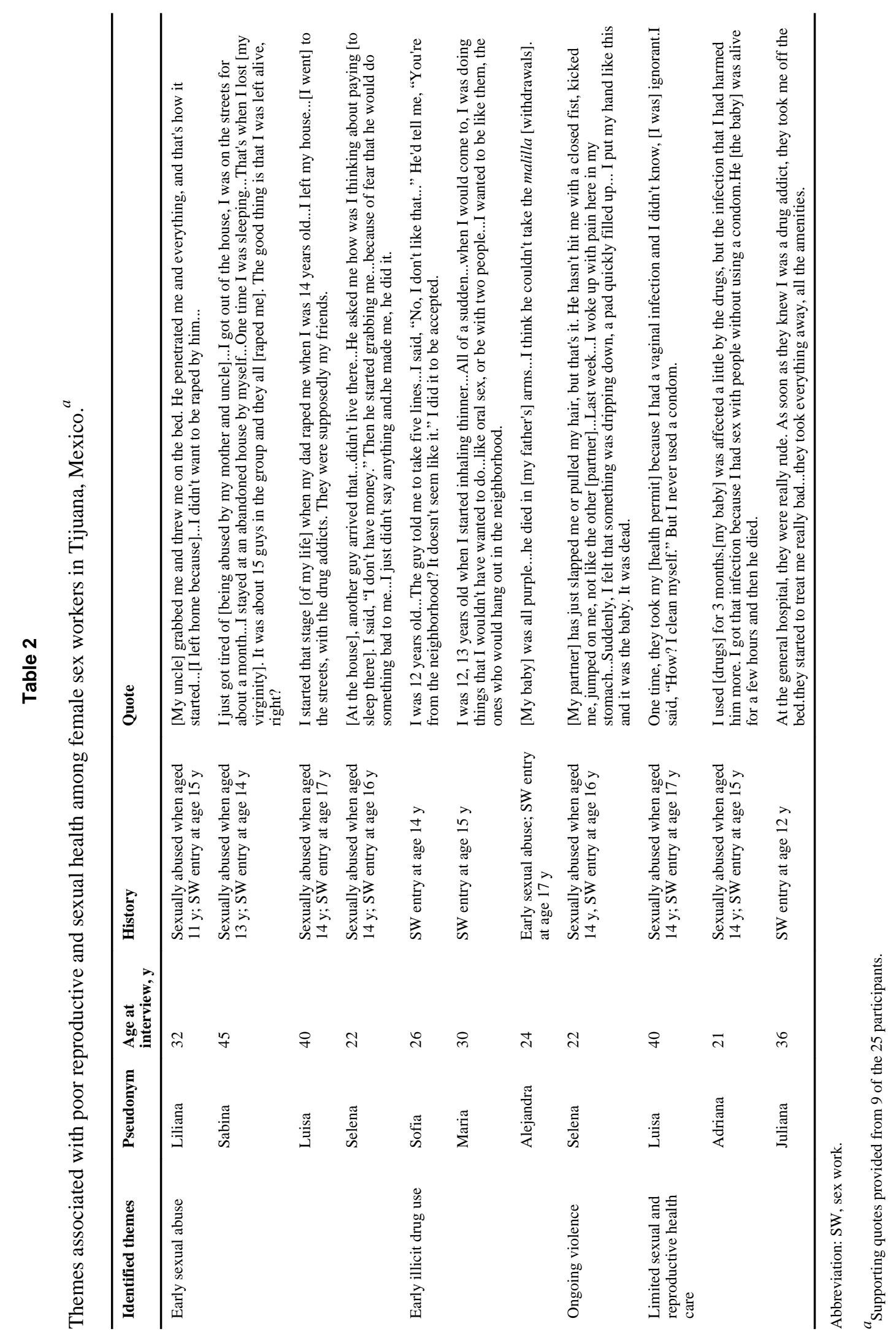

Int J Gynaecol Obstet. Author manuscript; available in PMC 2016 February 01. 